\title{
Optical observation of donor-bound excitons in hydrogen-implanted ZnO
}

\author{
J.-K. Lee ${ }^{\text {a) }}$ and M. Nastasi \\ Materials Science and Technology Division, Los Alamos National Laboratory, Los Alamos, \\ New Mexico 87545 \\ D. W. Hamby and D. A. Lucca \\ School of Mechanical and Aerospace Engineering, Oklahoma State University, Stillwater, Oklahoma 74078
}

(Received 20 December 2004; accepted 8 March 2005; published online 18 April 2005)

\begin{abstract}
The optical and structural properties of $\mathrm{H}$ or $\mathrm{He}$ implanted $\mathrm{ZnO}$ were investigated using low temperature photoluminescence (PL) and infrared spectroscopy (IR). H implantation is shown to influence the relative luminescence intensities of the donor bound excitons, enhancing the $3.361 \mathrm{eV}$ peak, and changing the overall intensity of the PL spectrum. PL from He implanted $\mathrm{ZnO}$ is used to demonstrate that implantation damage is partially responsible for the variations observed in the PL of $\mathrm{H}$ implanted $\mathrm{ZnO}$. IR spectra show that the increase in the relative intensity of the $3.361 \mathrm{eV}$ peak coincides with an appearance of the $\mathrm{H}$ vibrational mode in the $\mathrm{ZnO}$ lattice. Our results indicate that the implanted $\mathrm{H}$ forms $\mathrm{O}-\mathrm{H}$ bonds at $\mathrm{Zn}$ vacancies, and that it is these defect complexes which give rise to the shallow donors participating in the observed bound-exciton luminescence at $3.361 \mathrm{eV}$. (C) 2005 American Institute of Physics. [DOI: 10.1063/1.1906330]
\end{abstract}

As-grown $\mathrm{ZnO}$, in the nominally undoped state, typically exhibits $n$-type conductivity. In spite of intensive research, the origin of the $n$-type conductivity is still debated. It has been traditionally attributed to native defects in the ZnO. ${ }^{1}$ However, both experimental and theoretical studies have not clearly demonstrated that there is a native defect which behaves as a shallow donor in $\mathrm{ZnO}$. Recently, firstprinciples calculations have suggested that hydrogen acts as a source of $n$-type conductivity. ${ }^{2}$ Consistent with these calculations, several studies using electron paramagnetic resonance, Hall effect measurements, and muon spin spectroscopy have shown that there is a shallow H-related donor level just below the conduction band.,4

In this article, we investigate the effects of $\mathrm{H}$ implantation on the optical properties of $\mathrm{ZnO}$ using a combination of low temperature photoluminescence (PL) and multiple internal reflection infrared (MIR-IR) spectroscopies.

Commercially available $\mathrm{ZnO}$ single crystals were used in this work. ${ }^{5}$ The $(0001)$ surfaces were implanted with 6 $\mathrm{keV} \mathrm{H} \mathrm{H}^{+}$at doses of $2 \times 10^{13}, 3 \times 10^{14}$, and $5 \times 10^{15} \mathrm{H} / \mathrm{cm}^{2}$. At this energy the majority of the implanted $\mathrm{H}$ comes to rest at a depth between $40-110 \mathrm{~nm}$, which is believed to be within the absorption and emission depth for PL. This is the significant difference between our study and previous work regarding the effect of $\mathrm{H}$ implantation in $\mathrm{ZnO}$. ${ }^{6,7}$ Due to the high implantation energies ranging from $100 \mathrm{keV}$ to $1 \mathrm{MeV}$ in previous studies, the implanted $\mathrm{H}$ resided much deeper than the optically active region and showed only the effect of implantation induced damage on the optical properties of $\mathrm{ZnO}$. Half of the hydrogen-implanted samples were annealed in vacuum at $300{ }^{\circ} \mathrm{C}$ for $15 \mathrm{~min}$. To evaluate the role of the implantation damage on the PL spectrum of $\mathrm{ZnO}$, a companion set of room temperature implants was produced using 10 $\mathrm{keV} \mathrm{He}{ }^{+}$at a dose of $2.5 \times 10^{13} / \mathrm{cm}^{2}$, which according to the stopping and range of ions in matter (SRIM) simulations ${ }^{8}$ supplies the same amount of lattice damage as the $6 \mathrm{keV} \mathrm{H}^{+}$

${ }^{a}$ Author to whom all correspondence should be addressed; electronic mail: jklee@lanl.gov implantation at $3 \times 10^{14} / \mathrm{cm}^{2}$. PL was excited using the 351 $\mathrm{nm}$ line from an $\mathrm{Ar}^{+}$laser and the emitted light was detected with a $\mathrm{LN}_{2}$-cooled charge-coupled device camera. Infrared spectroscopy (IR) measurements in multiple internal reflection mode were performed at room temperature.

Figure 1 shows the change in the $4.2 \mathrm{~K} \mathrm{PL}$ spectra for $\mathrm{ZnO}$ as a function of $\mathrm{H}$ implantation dose. The boundexciton PL spectrum prior to implantation exhibits at least six narrow peaks with the strongest peak at $3.364 \mathrm{eV}$ measuring about $1 \mathrm{meV}$ full width at half maximum (FWHM), consistent with the previous work by Reynolds et al. ${ }^{9}$ After $\mathrm{H}$ implantation, the relative intensity of PL peaks changed. The intensity of the $3.361 \mathrm{eV}$ peak relative to that of the $3.364 \mathrm{eV}$ peak increased for all doses. In addition, the overall $\mathrm{PL}$ intensity of the $\mathrm{H}$ implanted $\mathrm{ZnO}$ showed a nonlinear variation with respect to the $\mathrm{H}$ implantation dose. While the $2 \times 10^{13} \mathrm{H} / \mathrm{cm}^{2}$ implantation increased the overall PL intensity, the $3 \times 10^{14}$ and $5 \times 10^{15} \mathrm{H} / \mathrm{cm}^{2}$ implantations decreased the intensity. The FWHM of the PL peaks increased with increasing $\mathrm{H}$ implantation dose, causing the wellresolved peaks observed in unimplanted $\mathrm{ZnO}$ to merge after

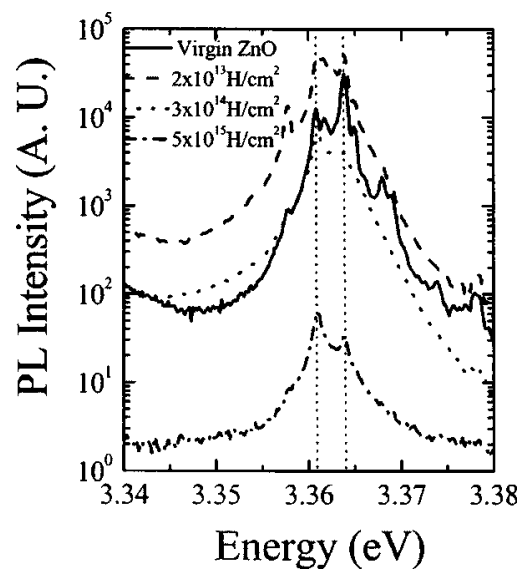

FIG. 1. PL spectra of unimplanted and $2 \times 10^{13}, 3 \times 10^{14}$, and 5 $\times 10^{15} \mathrm{H} / \mathrm{cm}^{2} \mathrm{H}$ implanted $\mathrm{ZnO}$ measured at $4.2 \mathrm{~K}$. 


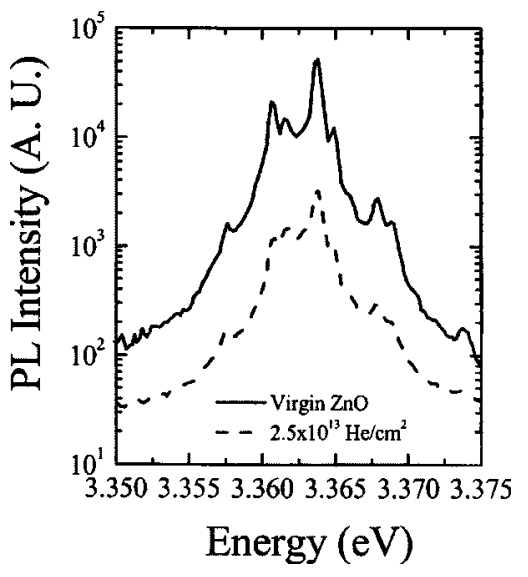

FIG. 2. PL spectra of He implanted $\mathrm{ZnO}$ measured at $4.2 \mathrm{~K}$.

the $5 \times 10^{15} \mathrm{H} / \mathrm{cm}^{2}$ implantation leaving only two broad PL peaks at 3.361 and $3.364 \mathrm{eV}$. (See Fig. 1)

PL measurements were also performed for $\mathrm{ZnO}$ implanted with He. Since there is no chemical interaction between $\mathrm{He}$ and $\mathrm{ZnO}$, changes in the PL spectra of this sample reflected ion implantation lattice damage. As shown in Fig. 2 a significant decrease in the PL intensity was observed following the He implantation, consistent with previous reports on the highly irradiated $\mathrm{ZnO} .{ }^{6,7}$ However, the relative intensity of the PL peaks remained unchanged and the peak at $3.364 \mathrm{eV}$ still exhibited the maximum intensity.

To elucidate the effect of $\mathrm{H}$ passivation, PL spectra were also obtained for dehydrogenated $\mathrm{ZnO}$. Figure 3 shows the PL spectra for $\mathrm{ZnO}$ that was implanted with 3 $\times 10^{14} \mathrm{H} / \mathrm{cm}^{2}$ and then thermally annealed. A comparison with Fig. 1 shows that the relative peak intensities as well as the overall intensity of the PL changed after annealing; the relative intensity between the 3.361 and $3.364 \mathrm{eV}$ peaks recovered to that of unimplanted $\mathrm{ZnO}$ and the overall PL intensity decreased to $15 \%$ of the PL intensity of $\mathrm{H}$ implanted $\mathrm{ZnO}$. The overall decrease in intensity following annealing indicates that defect formation occurs as a result of dehydrogenation and alters the luminescence mechanism by enhancing the non-radiative energy transfer process.

The bonding nature between $\mathrm{H}$ and lattice damaged $\mathrm{ZnO}$ was investigated using MIR-IR for as-grown and 3 $\times 10^{14} \mathrm{H} / \mathrm{cm}^{2} \mathrm{H}$ implanted $\mathrm{ZnO}$ crystals. In Fig. 4, two broad bands, which are centered between 3330 and

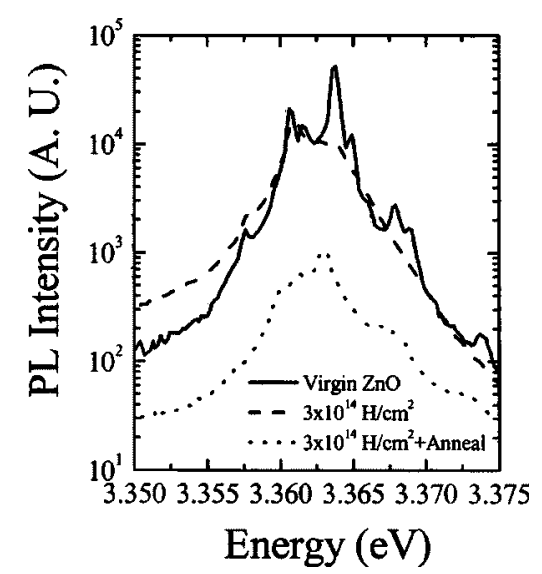

FIG 3 PL spectra of as-implanted and $300^{\circ} \mathrm{C}$ annealed $\mathrm{ZnO}$ for a dose of $3 \times 10^{14} \mathrm{H} / \mathrm{cm}^{2}$ measured at $4.2 \mathrm{~K}$.

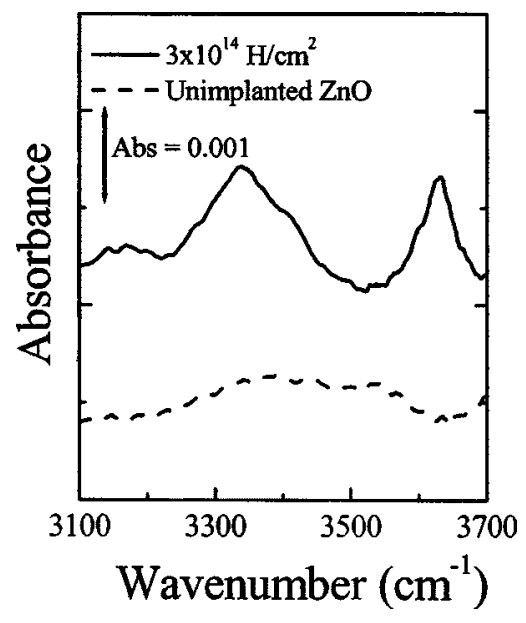

FIG. 4. Infrared (IR) spectra of as-grown and $\mathrm{H}$ implanted $\mathrm{ZnO}$ using MIR-IR geometry.

$3630 \mathrm{~cm}^{-1}$ were observed for the $\mathrm{H}$ implanted $\mathrm{ZnO}$. After dehydrogenation, the broad modes observed in the $\mathrm{H}$ implanted $\mathrm{ZnO}$ disappeared, demonstrating that the IR peaks above $3300 \mathrm{~cm}^{-1}$ were due to the local vibrations of $\mathrm{H}$ bound to $\mathrm{ZnO}$.

These data show that implanted $\mathrm{H}$ has a complex effect on the luminescence of $\mathrm{ZnO}$. $\mathrm{H}$ implantation under a critical dose promotes the radiative recombination process in $\mathrm{ZnO}$ and increases the overall intensity of luminescence. However, after annealing at $300{ }^{\circ} \mathrm{C}$, the PL intensity of $\mathrm{H}$ implanted $\mathrm{ZnO}$ decreased by an order of magnitude, suggesting incomplete recovery or passivation of the lattice damage caused by ion implantation. While $300{ }^{\circ} \mathrm{C}$ is sufficient to allow the implanted $\mathrm{H}$ to escape partially from $\mathrm{ZnO}$ crystals, ${ }^{10}$ it is not sufficient to remove most of the defects formed during ion implantation. This suggests that the decrease in PL intensity for annealed $\mathrm{ZnO}$ was due to $\mathrm{H}$ loss and the presence of unpassivated defects. Hence, the observed increase in PL intensity for $2 \times 10^{13} \mathrm{H} / \mathrm{cm}^{2}$ implanted $\mathrm{ZnO}$ is most likely due to passivation of grown-in or intrinsic defects. An increase in the overall PL intensity following $\mathrm{H}$ incorporation in $\mathrm{ZnO}$ has been observed by several groups. Ohashi et al. proposed that implanted $\mathrm{H}$ passivated the unintentionally doped acceptors and defects, leading to the increase in the PL intensity. ${ }^{11}$ Polyakov et al., however, attributed the increase of the PL intensity and electron concentration to either the presence of $\mathrm{H}$ shallow donors or $\mathrm{H}$ donor complexes bound to native defects. ${ }^{12}$ Recently, Seager and Myer demonstrated that the incorporated $\mathrm{H}$ passivated most of the acceptor states and introduced a shallow donor level. ${ }^{13}$ For $\mathrm{H}$ implantation at and above 3 $\times 10^{14} \mathrm{H} / \mathrm{cm}^{2}$, a decrease in the total luminescence efficiency is observed, which we attribute to an increase in the concentration of the nonradiative centers produced by the ion implantation. It is apparent that irradiation defects contribute to the nonradiative process and suppress the luminescence process. However, it is noted that the shape of the PL spectra for the $3 \times 10^{14} \mathrm{H} / \mathrm{cm}^{2}$ implanted $\mathrm{ZnO}$ and the He implanted $\mathrm{ZnO}$ was different, although both conditions exhibit significantly decreased PL. The luminescence with the maximum intensity was found at $3.361 \mathrm{eV}$ for $\mathrm{H}$ and at $3.364 \mathrm{eV}$ for $\mathrm{He}$ implanted $\mathrm{ZnO}$, respectively. This suggests that the change in the relative intensity of the 3.361 and $3.364 \mathrm{eV}$ peaks cannot 
be exclusively attributed to the formation of irradiation defects.

As shown in Fig. 1, $\mathrm{H}$ implantation changed the relative intensities of the PL peaks, with the intensity of $3.361 \mathrm{eV}$ peak becoming stronger relative to the $3.364 \mathrm{eV}$ peak regardless of implantation dose or implantation damage. However, when implanted $\mathrm{H}$ started to be evolved from the $\mathrm{ZnO}$ crystals through annealing, the maximum intensity peak reverted to the $3.364 \mathrm{eV}$ peak. Since both the 3.361 and $3.364 \mathrm{eV}$ peaks are attributed to neutral donor bound excitons, these results suggest that the concentration of the donors responsible for the luminescence at $3.361 \mathrm{eV}$ is very sensitive to the presence of hydrogen.

The IR peaks observed at 3330 and $3630 \mathrm{~cm}^{-1}$ in $\mathrm{H}$ implanted $\mathrm{ZnO}$ (Fig. 4) provide additional support for $\mathrm{H}$ being a shallow donor. Based on recent experimental observations together with predictions from first-principles calculations, the mode ranging from 3300 to $3400 \mathrm{~cm}^{-1}$ was assigned to a $\mathrm{O}-\mathrm{H}$ bond where $\mathrm{H}$ occupies a $\mathrm{Zn}$ vacancy or an antibonding configuration, and the mode ranging from 3600 to $3700 \mathrm{~cm}^{-1}$ was assigned to an interstitial $\mathrm{H}$ atom in a bond centered (BC) site. ${ }^{13-15}$ Our observation in the present work of two modes centered at 3330 and $3630 \mathrm{~cm}^{-1}$ is consistent with these previous reports, and indicates $\mathrm{H}$ bonding occurs in the $\mathrm{H}$ implanted $\mathrm{ZnO}$. The simultaneous relative increase in the $3.361 \mathrm{eV}$ luminescence peak and the appearance of the $\mathrm{H}$ vibration modes in $\mathrm{ZnO}$ indicates that implanted $\mathrm{H}$ that becomes chemically bonded to the $\mathrm{ZnO}$ lattice is responsible for the recombination of donor-bound excitons, and that this recombination is the source of the 3.361 eV PL peak.

A remaining question is the bonding configuration of the $\mathrm{H}$ in $\mathrm{H}$ implanted $\mathrm{ZnO}$ that gives rise to the $3.361 \mathrm{eV} \mathrm{PL}$ peak. It has already been established that the $3.364 \mathrm{eV}$ PL peak is due to hydrogen-related-donor-bound excitons. This conclusion is based on several factors including an observed correlation between the $3.364 \mathrm{eV}$ PL peak intensity and increased $n$-type conductivity in hydrogenated $\mathrm{ZnO}^{16,17}$ and the fact that this peak is predominately observed in $\mathrm{ZnO}$ crystals that have been grown in or treated with hydrogen. However, $\mathrm{ZnO}$ consistently exhibits strong $n$-type conductivity and a $3.361 \mathrm{eV}$ PL peak even when grown in low hydrogen environments. Still, both the 3.361 and $3.364 \mathrm{eV} \mathrm{PL}$ peaks are sensitive to dehydrating thermal treatments. The observed intensity reduction of these peaks following a high temperature anneal, ${ }^{9,18}$ further suggests that $\mathrm{H}$ participates in both the 3.364 and $3.361 \mathrm{eV}$ luminescence.

Van de Walle has shown that two kinds of hydrogen bonding can act as a shallow donor in $\mathrm{ZnO}$ : $\mathrm{H}$ in the bondcentered (BC) configuration and $\mathrm{H}$ bound to native defects. ${ }^{2}$ First-principles and experimental studies of native defects in $\mathrm{ZnO}$ have predicted that the most stable (lowest formation energy) native defect in $\mathrm{ZnO}$ is the $\mathrm{Zn}$ vacancy, ${ }^{19,20}$ which together with Van de Walle's findings suggest that the most likely $\mathrm{H}$ - native defect responsible for the $3.361 \mathrm{eV}$ luminescence is the $\mathrm{Zn}$ vacancy-H complex. Structural defects in $\mathrm{ZnO}$, such as $\mathrm{Zn}$ and $\mathrm{O}$ vacancies are expected to behave as deep acceptors and deep donors, respectively. However, $\mathrm{H}$ in a $\mathrm{Zn}$ vacancy bonds with surrounding oxygen atoms. The strength of the $\mathrm{O}-\mathrm{H}$ bond in $\mathrm{ZnO}$ greatly reduces the energy for forming a hydrogen donor (i.e., $\mathrm{H}^{+}$formation), making a $\mathrm{Zn}$ vacancy-H complex act as a shallow donor. Here, it is worth recalling that $\mathrm{H}$ implantation naturally creates defects, such as vacancies and interstitials, and that the intensity of the $3.361 \mathrm{eV}$ PL peak relative to that of the $3.364 \mathrm{eV} \mathrm{PL}$ peak was observed to increase for only $\mathrm{H}$ implanted $\mathrm{ZnO}$ and not for $\mathrm{He}$ implanted $\mathrm{ZnO}$. We thus conclude that $\mathrm{H}$ forms defect complexes with native or implantation induced $\mathrm{Zn}$ vacancies and is responsible for the $3.361 \mathrm{eV}$ PL peak while $\mathrm{H}$ in the $\mathrm{BC}$ configuration causes the $3.364 \mathrm{eV}$ PL peak in $\mathrm{ZnO}$ as suggested by previous studies.

The Los Alamos portion of this work has been supported by the U.S. Department of Energy, Office of Basic Energy Sciences. We also thank D. Wayne Cooke, G. Cantwell and B. Haskins for their discussion and help. Financial support provided to OSU by the NSF under Grant No. DMI-0100318 and the Oklahoma Center for the Advancement of Science and Technology are greatly appreciated.

${ }^{1}$ D. C. Look, J. W. Hemsky, and J. R. Sizelove, Phys. Rev. Lett. 82, 2552 (1999).

${ }^{2}$ C. G. Van de Walle, Phys. Rev. Lett. 85, 1012 (2000).

${ }^{3}$ S. F. J. Cox, E. A. Davis, S. P. Cottrell, P. J. C. King, J. S. Lord, J. M. Gil, H. V. Alberto, R. C. Vilão, J. P. Duarte, N. Ayres de Campos, A. Weidinger, R. L. Lichti, and S. J. C. Irvine, Phys. Rev. Lett. 86, 2601 (2001).

${ }^{4}$ D. M. Hofmann, A. Hofstaetter, F. Leiter, H. Zhou, F. Henecker, B. K. Meyer, S. B. Orlinskii, J. Schmidt, and P. G. Baranov, Phys. Rev. Lett. 88, 045504 (2002)

${ }^{5}$ D. C. Look, D. C. Reynolds, J. R. Sizelove, R. L. Jones, C. W. Litton, G. Cantwell, and W. C. Harsch, Solid State Commun. 105, 399 (1998).

${ }^{6}$ K. Ip, E. Overberg, Y. W. Heo, D. P. Norton, S. J. Pearton, S. O. Kucheyev, C. Jagadish, J. S. Williams, R. G. Wilson, and J. M. Zavada, Appl. Phys. Lett. 81, 3996 (2002).

${ }^{7}$ D. J. Brink and H. W. Kunert, Phys. Status Solidi A 229, 859 (2002).

${ }^{8}$ J. F. Ziegler, J. P. Biersack, and U. Littmark, The Stopping and Range of Ions in Solids, (Pergamon, New York, 1985).

${ }^{9}$ D. C. Reynolds, D. C. Look, B. Jogai, C. W. Litton, T. C. Collins, W. Harsch, and G. Cantwell, Phys. Rev. B 57, 12151 (1998).

${ }^{10}$ K. Ip, E. Overberg, Y. W. Heo, D. P. Norton, S. J. Pearton, C. E. Stutz, B. Luo, F. Ren, D. C. Look, and J. M. Zavada, Appl. Phys. Lett. 82, 385 (2003).

${ }^{11}$ N. Ohashi, T. Ishigaki, N. Okada, T. Sekiguchi, I. Sakaguchi, and H. Haneda, Appl. Phys. Lett. 80, 2869 (2002).

${ }^{12}$ A. Y. Polyakov, N. B. Smirnov, A. V. Govorkov, K. Ip, M. E. Overberg, Y. W. Heo, D. P. Norton, S. J. Pearton, B. Luo, F. Ren, and J. M. Zavada, J. Appl. Phys. 94, 400 (2003)

${ }^{13}$ C. H. Seager and S. M. Myer, J. Appl. Phys. 94, 2888 (2003).

${ }^{14}$ E. V. Lavrov, J. Weber, F. Börrnert, C. G. Van de Walle, and R. Helbig, Phys. Rev. B 66, 165205 (2002).

${ }^{15}$ M. D. McCluskey, S. J. Jokela, K. K. Zhuravlev, P. J. Simpson, and K. G. Lynn, Appl. Phys. Lett. 81, 3807 (2002).

${ }^{16}$ Y. M. Strzhemechny, H. L. Mosbacker, D. C. Look, D. C. Reynolds, C. W. Litton, N. Y. Garces, N. C. Giles, L. E. Halliburton, S. Niki, and L. J. Brillson, Appl. Phys. Lett. 84, 2545 (2004).

${ }^{17}$ H. Alves, D. Pfisterer, A. Zeuner, T. Riemann, J. Christen, D. M. Hofmann, and B. K. Meyer, Opt. Mater. (Amsterdam, Neth.) 23, 33 (2003).

${ }^{18}$ B. K. Meyer, H. Alves, D. M. Hofmann, W. Kriegseis, D. Forster, F. Bertram, J. Christen, A. Hoffmann, M. Straßburg, M. Dworzak, U. Haboeck, and A. V. Rodina, Phys. Status Solidi A 229, 859 (2002).

${ }^{19}$ A. F. Kohan, G. Ceder, D. Morgan, and C. G. Van de Walle, Phys. Rev. B 61, 015019 (2000).

${ }^{20}$ Z. Q. Chen, S. Yamamoto, M. Maekawa, A. Kawasuso, X. L. Yuan, and T. Sekiguchi, J. Appl. Phys. 94, 4807 (2003). 